\title{
Computational and experimental analysis of timber beams with different types of flaws
}

Cite as: AIP Conference Proceedings 2309, 020036 (2020); https://doi.org/10.1063/5.0034413

Published Online: 30 November 2020

J. Kováčiková, O. Ivánková, S. Berg, M. Ekevad, and T. Klas
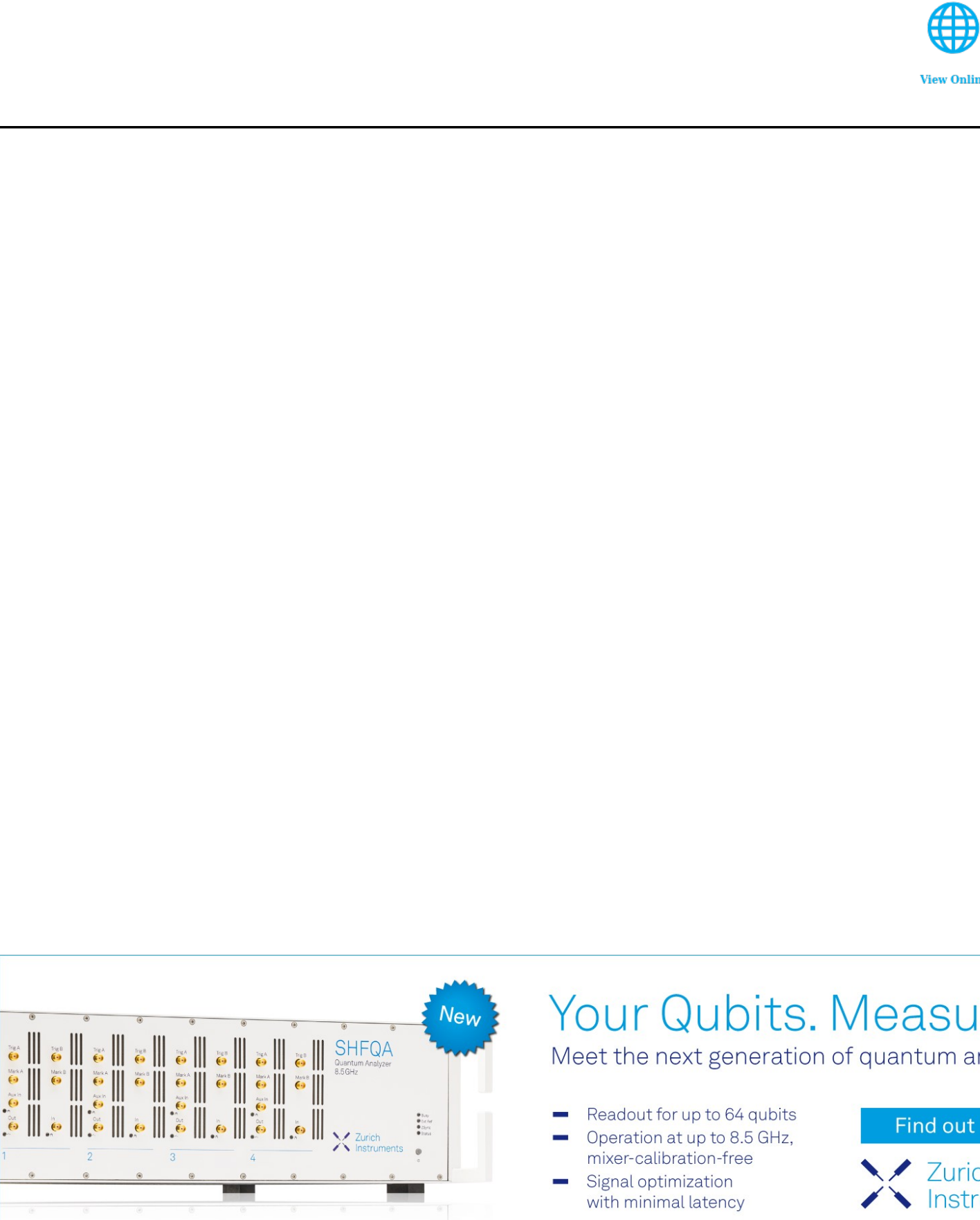

Your Qubits. Measured.

Meet the next generation of quantum analyzers

- Readout for up to 64 qubits

- Operation at up to $8.5 \mathrm{GHz}$. mixer-calibration-free

- Signal optimization with minimal latency 


\title{
Computational and Experimental Analysis of Timber Beams with Different Types of Flaws
}

\author{
J. Kováčiková ${ }^{1, \text { a }}$, O. Ivánková2, b, S. Berg ${ }^{3, \text { c }}$, M. Ekevad ${ }^{3, \text { d, }}$, T. Klas², e \\ ${ }^{1}$ Department of Mechanical Engineering, Linnaeus University, 35195 Växjö, Sweden \\ ${ }^{2}$ Department of Structural Mechanics and ${ }^{b 2}$ Department of Steel and Timber Structures, Slovak University of \\ Technology in Bratislava, Radlinského 11, 81005 Bratislava, Slovak Republic \\ ${ }^{3}$ Department of Engineering Sciences and Mathematics, Luleå University of Technology, Forskargatan 1, 93187 \\ Skellefteå, Sweden \\ a)Corresponding author: janka.kovacikova@lnu.se \\ b)olga.ivankova@stuba.sk \\ c)sven.berg@ltu.se \\ d)mats.ekevad@ltu.se \\ e)tomas.klas@stuba.sk
}

\begin{abstract}
This work was focused on the experimental testing and finite element analysis (FEA) of timber beams with and without flaws (different types of cracks and hole). The aim was analysing the effect of flaws on their load-carrying capacity. This topic is important for designers of timber constructions, since even today there is still a lack of knowledge in the field of fracture mechanics of wood. The results from experimental testing and numerical simulations were discussed in this paper. Two wood products were analysed, namely, sawn and glued laminated beams (glulam beams) and three types of flaws were considered for both products i.e. a vertical crack, an oblique crack and a circular hole. In addition for glulam beams the horizontal crack in the glue line was considered. Four-point bending test was created for experimental testing considering quasi-brittle characteristic of wood. 4 samples for each type of beam, 36 in total. XFEM (Extended Finite Element Method) was used for finite element analysis of beams with considering orthotropic-elastic properties for glulam beams were considered and The results of mechanical tests and FEA gave us an overview on how different types of flaws influence the load-carrying capacity of sawn and glulam beams and with what accuracy we can simulate cracks in wood using computational method.
\end{abstract}

\section{INRODUCTION}

The knowledge on how flaws influence the beams' response on loading is essential for engineers when they design support members in our technologically developed society. Flaws can cause the ultimate failure of the support member and/or whole construction, therefore is needed that designers know how to use software on FEA basis. Even though the software nowadays is powerful time saving tool, 3D FEA of fracture mechanics of wooden structures with flaws it is less commonly solve than most of the isotropic materials, and in addition there is a lack of information, and standards for analysing influence of flaws in timber structures.

Fracture resistance is the ability of materials to withstand flaws that initiate failure, and usually we consider fracture toughness (based on Griffith's approach) or critical value of energy release rate (based on Irwin's approach) [1]. A material's fracture resistance value varies depending on the loading mode. Three different modes of loading of a crack are known: mode I (opening mode), mode II (in-plane shear mode); and mode III (out-of-plane shear mode). If crack is loaded combination of modes it is mixed mode.

In wood, it is important to consider not only mode of loading but also a plane in which the crack lie and direction in which the crack may propagate. It can be in one or two directions of each plane with considering three planes [2].

Fracture and Damage Mechanics

AIP Conf. Proc. 2309, 020036-1-020036-8; https://doi.org/10.1063/5.0034413

Published by AIP Publishing. 978-0-7354-4045-6/\$30.00 
The orthotropic structure of wood gives six orientations in which the crack may lie (RL, TL, LR, TR, LT, and RT) (Fig.1) and since there are three modes to consider, we can identify 18 basic fracture situations [3].

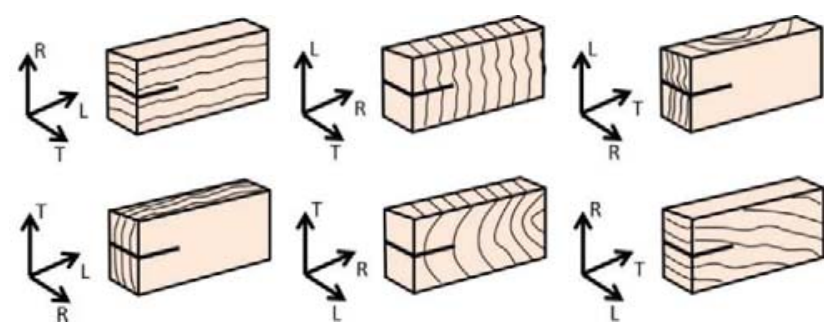

FIGURE 1. The crack propagation system in wood

It is a challenging task to understand the fracture behaviour of quasi- brittle material such as wood, especially, when it is a 3-D problem, however deeper knowledge how to simulate flaws in timber structures can help to optimize a design process. The aim of this study was to investigate the load bearing capacity of flawed sawn and glulam beams and to find a model that could predict failure load of beams due to cracks. XFEM and an orthotropic elastic FE-model was used and a four-point bending test with pre-manufactures flaws was done and used for evaluation.

\section{MATERIAL AND METHODS}

\section{Theory}

In the four-point bending test the theoretical bending failure load was determined using conventional calculation methods and using a maximum value of bending stress of $24 \mathrm{MPa}\left(\sigma_{\max }\right)$, the theoretical load can be determined as shown in Equation 1. Assuming that the bending strength sets the limit for the load-bearing capacity and using ordinary beam theory, the ultimate load $\mathrm{F}_{\mathrm{u}}$ is given by:

$$
F_{u}=\left(2 b d^{2} 2 \sigma_{\max }\right) /\left(3\left(L-L_{i}\right)\right.
$$

Where: $F_{u}$ is the ultimate load at fracture, $L$ is the length of the support span, $L_{i}$ is distance between the applied loads, $\mathrm{b}$ is width, $\mathrm{d}$ is thickness and $\sigma_{\max }$ the flexural stress.

The fracture mechanics design approach is considered [1]. The approach takes in consideration three important variables: applied stress, flaw, and fracture toughness. In this work, the energy criterion approach is used for FEA analysis. It is Irwin's [4] extension of Griffith's [5] stress intensity approach and it states that crack will extent when the energy required for the crack growth overcome the resistance of the material:

$$
\mathrm{G} \geq \mathrm{G}_{\mathrm{C}}
$$

Where: $\mathrm{G}$ is crack driving force, $\mathrm{G}_{\mathrm{c}}$ is critical value of the energy release-fracture resistance of material.

Fracture toughness is determined from values of stress intensity factors (SIFs) in different modes. The stress intensity factor is usually given to denote the mode of loading, i.e., KI, KII and KIII It is possible to find some closed formulas for solving SIFs which are presented in fracture mechanics handbooks [6, 7]. Their values depend on stress fields ahead of a crack tip, mode of a loading, shape of a flaw, and applied load. Although values of SIFs are given in different forms, $\mathrm{K}$ is always related to correction factor:

$$
\mathrm{K}_{(\mathrm{I}, \mathrm{II}, \mathrm{II})}=\mathrm{Y} \sigma \sqrt{\pi \mathrm{a}}
$$

Where: $\sigma$ is characteristic stress, a is dimension of a crack, and $\mathrm{Y}$ is unit less constant that depends on the geometry and the mode of loading.

Following relationship between SIFs and value of energy release rate is taken under consideration:

$$
\mathrm{G}=\frac{\mathrm{K}_{1}^{2}}{\mathrm{E}^{\prime}}+\frac{\mathrm{K}_{\mathrm{II}}^{2}}{\mathrm{E}^{\prime}}+\frac{\mathrm{K}_{1}^{2}}{2 v}
$$


Where: $\mathrm{E}^{\prime}=\mathrm{E}$ for plane stress, $\mathrm{E}^{\prime}=\mathrm{E} /\left(1-v^{2}\right)$ for plane strain, and $\mathrm{E}$ is Young's modulus, $v$ is Poisson's ratio, $\mathrm{K}_{\mathrm{i}}$ stress intensity factors for mode I, II, and III respectively.

It is possible to obtain the value of critical energy release rate $G_{c}$ through values of fracture toughness $K_{C}$. The critical energy release rate can have three different values depending on the mode of loading ( $\left.\mathrm{G}_{\mathrm{CI}}, \mathrm{G}_{\mathrm{CII}}, \mathrm{G}_{\mathrm{CIII}}\right)$.

\section{Experiments and experimental set-up}

In total, 36 different beams were tested, four beams in each experiment. Four different pre-produced flaws to each type of the flaw were tested together with a flawless beam as reference for sawn beams (labelled N) and glued laminated beams (labelled LN). N beams were class C24 classification according [8], and LN beams class GL 24c according [9]. Both were made of spruce. LN beams were construed using 4 lamellas glued using a Melamine Urea Formaldehyde Adhesive Type I [10], (Casco 1247/2526). The dimensions of tested beams were 1700x100x160mm. Lamellas of glued laminated beams were $40 \mathrm{~mm}$ thick. The experimental set-up was a four-point beam bending test, see Fig. 2. The distance between the supports was $1.4 \mathrm{~m}$. To reduce the risk of wood compression damages $0.3 \mathrm{~m}$ long steel plates were placed at supports and under the load, respectively. The load was applied $0.650 \mathrm{~m}$ from the ends the beam and $0.5 \mathrm{~m}$ from the support.

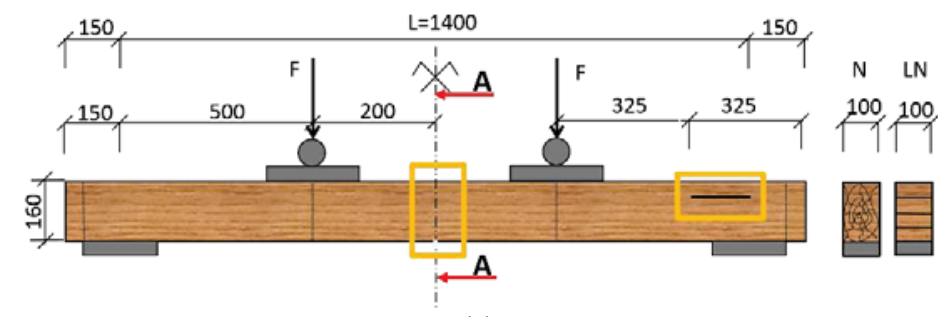

(a)

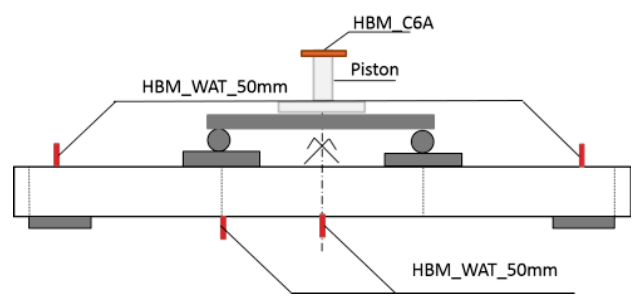

(b)

FIGURE 2. (a) Set-up of four-point bending test, (b) Positions of sensors

A hydraulic load cell was used for measuring force with sensor HBM_C6A_1MN and measuring range 3mV/V. Loading velocity was $200.00 \mathrm{~ms}(5 \mathrm{~Hz})$. All the experiments were conducted using four inductive displacement transducers, type WA T 50mm from HBM, for measuring deflections with measuring range $125 \mathrm{mV} / \mathrm{V}$. One was placed where the force was applied, one in the middle of the beam's span and two at the place of supports. Full bridge transducer type was used, see Fig. 2 (b).

Figure 3 shows all the different flaw types for both sawn and glued laminated beams: Experiments with flaws (ad) were executed on both sawn and glulam beams, experiment with the fifth flaw was studied only for the glued laminated beams.

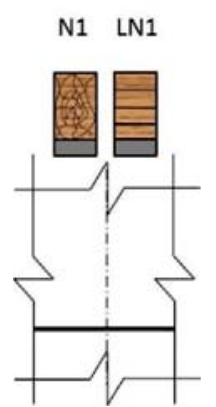

a)

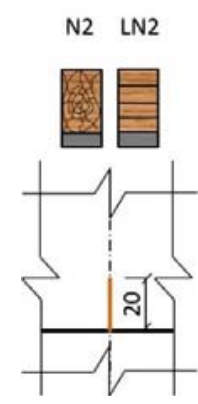

(b)

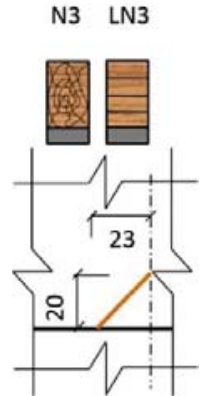

(c)

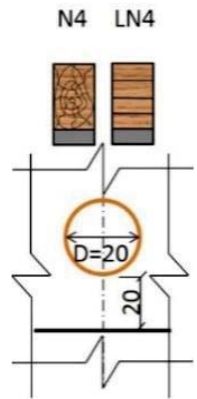

(d)

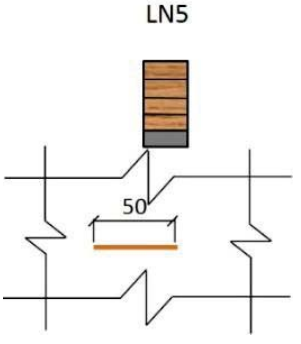

(e)

FIGURE 3. Types of flaw in the studied: (a) beam without a flaw, (b) beam with a straight vertical crack $20 \mathrm{~mm}$ deep in the middle of the beam's span, (c) beam with an oblique crack 20 by $23 \mathrm{~mm}$ with a tip in the middle of beam `s span, (d) beam with a circular hole, and (e) a beam with a horizontal crack of $50 \mathrm{~mm}$.

The beams were loaded until failure occurred. Then the load-deflection and maximal forces for each beam were recorded. Two specific values of deflection in experimental testing was looked at, the ultimate deflection under ultimate force, and deflection under maximal bending force $F_{\max , \mathrm{b}}(4)$. 
The value of bending force was obtained from formula for the beam loaded by two equal forces, equally spaced from the beam's edges with considering the design requirements in Eurocode 5 [11].

$$
\mathrm{F}_{\max , \mathrm{b}}=\frac{\mathrm{M}_{\max }}{\mathrm{a}}
$$

Where: a is distance from a fix point to applied force, $\mathrm{M}_{\max }=\mathrm{f}_{\mathrm{m}, \mathrm{k}} * \mathrm{~W}$ is maximum bending moment, $\mathrm{W}$ is section modulus of rectangle; $\mathrm{f}_{\mathrm{m}, \mathrm{k}}$ is characteristic value of bending strength (24MPa).

\section{Finite element model}

The orthotropic-elastic model was used, the elastic properties for the glulam beams being taken from Eurocode 5 [11]. $\mathrm{E}_{\mathrm{RR}}, \mathrm{E}_{\mathrm{TT}}$ and $\mathrm{E}_{\mathrm{LL}}$ are the Young's moduli in the R, T and L directions, respectively, and $\mathrm{G}_{\mathrm{RT}}$, $\mathrm{G}_{\mathrm{TL}}$ and $\mathrm{G}_{\mathrm{LR}}$ are the shear moduli in the RT, TL and LR directions, respectively. Poisson's ratios were set to zero as stated in Eurocode 5. It was used as basis as it is used in industry to calculate on wooden structures. Moisture and temperature were neglected. For solid sawn beams (N) values were taken from wood handbook [2] and are shown in the Table. 1.

In second part of the study, simulations of beams were conducted in Abaqus 6.14-4. Value of the ultimate deflection was obtained experimentally and was used as a loading force in FEA simulations, by other words the deflection-loading control was used in simulations. Deflection values are following: $12.9 \mathrm{~mm}, 13.7 \mathrm{~mm}$ for N1, LN1 respectively; $12.8 \mathrm{~mm}, 11,5 \mathrm{~mm}$ for $\mathrm{N} 2$, LN2 respectively; $21.7 \mathrm{~mm}, 8.7 \mathrm{~mm}$ for N3, LN3 respectively; 20.9mm, $18.8 \mathrm{~mm}$ for N4, LN4 respectively; and $17.7 \mathrm{~mm}$ for LN5.

TABLE 1. Engineering constants for describing material properties of beams

\begin{tabular}{|c|c|c|c|c|c|c|c|c|c|c|}
\hline \multirow{3}{*}{ Label } & \multirow{3}{*}{$\begin{array}{l}\text { Density } \\
\rho \\
{\left[\mathrm{kg} / \mathrm{m}^{3}\right]}\end{array}$} & \multicolumn{3}{|c|}{ Modulus of Elasticity } & \multicolumn{3}{|c|}{ Poisson's ratio } & \multicolumn{3}{|c|}{ Shear modulus } \\
\hline & & \multicolumn{3}{|c|}{ [MPa] } & \multicolumn{2}{|c|}{$[-]$} & & \multicolumn{3}{|c|}{$[\mathrm{MPa}]$} \\
\hline & & $E_{L L}=E_{11}$ & $E_{R R}=E_{22}$ & $\mathrm{E}_{\mathrm{TT}}=\mathrm{E}_{33}$ & $v_{\mathrm{LR}}=v_{12}$ & $v_{\mathrm{LT}}=v_{13}$ & $v_{\mathrm{RT}}=v_{23}$ & $\mathrm{G}_{\mathrm{LR}}=\mathrm{G}_{12}$ & $\mathrm{G}_{\mathrm{LT}}=\mathrm{G}_{13}$ & $\mathrm{G}_{\mathrm{RT}}=\mathrm{G}_{13}$ \\
\hline $\mathbf{N}$ & 350 & 10700 & 710 & 430 & 0.38 & 0.51 & 0.31 & 500 & 620 & 23 \\
\hline LN & 385 & 11000 & 300 & 300 & $0^{*}$ & $0^{*}$ & $0^{*}$ & 650 & 650 & 23 \\
\hline
\end{tabular}

\section{Crack initiation and propagation}

Extended finite element method (XFEM) was used for analysing fracture behaviour of beams. In this method, it is not necessary use finer mesh in the shape of flaw and we are able to simulate stable crack propagation. It is numerical method based on the partition of unity method and generalized finite element method. Method uses differential equations with discontinuous functions [12, 13, and 14]. Crack was placed in TR plane and Mode I was considered for first four types of beams. For fifth type of beam, mixed mode was considered and crack was placed in RL plane. Two crack initiation criteria were specified which refers to beginning of crack propagation: maximum principal and nominal stress criterion. The crack begins to grow when the stress satisfy the initiation criteria.

Maximum principal stress criterion is established as:

$$
\mathrm{f}=\left\{\frac{\left\langle\sigma_{\max }\right\rangle}{\sigma_{\max }^{\mathrm{o}}}\right\}
$$

Where: $\sigma^{0}{ }_{\max }$ represents the maximum allowable principal stress.

Maximum nominal stress criterion is represented as:

$$
\mathrm{f}=\left\{\frac{\left\langle\mathrm{t}_{\mathrm{n}}\right\rangle}{\mathrm{t}_{\mathrm{n}}^{\mathrm{o}}}, \frac{\mathrm{t}_{\mathrm{s}}^{\mathrm{o}}}{\mathrm{t}_{\mathrm{s}}^{\mathrm{o}}}, \frac{\mathrm{t}_{\mathrm{t}}}{\mathrm{t}_{\mathrm{t}}^{\mathrm{o}}}\right\}
$$

Where: the nominal traction stress vector, $\mathrm{t}$, consists of three components. $\mathrm{t}_{\mathrm{n}}$ is the component normal to the likely cracked surface, and $t_{s}$ and $t_{t}$ are the two shear components on the likely cracked surface. Components $t_{i}$ are peak 
values of the nominal stress. In both (MAXPS, MAXS) criteria, the symbol \langle\rangle represents the Macaulay bracket with the usual interpretation. The Macaulay brackets are here to represent that a purely compressive stress does not initiate damage. Damage is assumed to initiate when ratio of maximum principal stress (Eq. 4, 5) reaches value of one [9].

These criteria were considered since bending and shear failures are typical for beams. Criteria for both sawn (N) and glued laminated beams (LN) were MAXPS= 24MPa and MAXS Normal- only mode and First direction 24MPa and Second direction MAXS criteria were 4.6 MPa, 4.2 MPa for N, LN respectively. The fracture criterion was defined with considering Virtual Crack Closure Technique (VCCT). This approach was used to simulate crack propagation along an arbitrary, solution-dependent path without (N1, LN1) and with (N2-N4, LN2-LN5) an initial crack. For computing the equivalent fracture energy release rate, the BK law was used. The BK law model was described by Benzeggagh and Kenane [15] and following formula describes this law:

$$
\frac{\mathrm{G}_{\text {equiv }}}{\mathrm{G}_{\text {equiv }}}=\mathrm{G}_{\mathrm{IC}}+\left(\mathrm{G}_{\mathrm{IIC}}-\mathrm{G}_{\mathrm{IC}}\right)+\left(\frac{\mathrm{G}_{\mathrm{II}}+\mathrm{G}_{\mathrm{III}}}{\mathrm{G}_{\mathrm{I}}+\mathrm{G}_{\mathrm{II}}+\mathrm{G}_{\mathrm{III}}}\right)^{\eta}
$$

Where GIC, GIIC, GIIIC are critical values of the energy release rate corresponding to mode I, mode II and mode III and are assumed constant.

This model provides a power law relationship combining energy release rates in crack loading modes into a single scalar fracture criterion. Following critical values of the energy release rate were chosen: $\mathrm{G}_{\mathrm{IC}}=176 \mathrm{~N} / \mathrm{m}, \mathrm{G}_{\text {IIC }}=734 \mathrm{~N} / \mathrm{m}$. These experimental values were retrieved from [16]. Value of $\mathrm{G}_{\text {IIIC }}$ was considered $10000 \mathrm{~N} / \mathrm{m}$ [7]

Resulting ultimate forces in XFEM were obtained by analysing dissipation energy and load-deflections diagrams. Ultimate force was force where a considerable jump in dissipation energy comes into view.

\section{Simulation model}

The FE calculations were carried out using the standard FE-code Abaqus 1x.x. with a cylindrical, linear elastic orthotropic material model. C3D8 element type was used for enrichment areas and C3D8R element type for other parts were used in simulations. Problem size of simulations is shown in Tab. 2. Interaction between a glue line and lamella was created using surface to surface contact, with considering small sliding. Tangential behaviour was considered friction less. Hard contact was chosen for describing normal behaviour. Global coordinate system LRT was used where $\mathrm{L}=1=\mathrm{X}, \mathrm{R}=2=\mathrm{Y}, \mathrm{T}=3=\mathrm{Z}$ and also local coordinate systems were assigned for lamellas in glulam beams describing material orientation.

TABLE 2. Problem size

\begin{tabular}{|l|l|l|l|l|}
\hline Label & Approach & Number of elements & Number of nodes & Number of variables \\
\hline N1 & XFEM & 51676 & 111850 & 265314 \\
\hline N2 & \multirow{2}{*}{ XFEM } & 60692 & 64404 & 142188 \\
\hline N3 & 117260 & 180568 & 428196 \\
\hline N4 & & 60884 & 131666 & 316158 \\
\hline LN1 & XFEM & 40692 & 64404 & 142188 \\
\hline LN2 & \multirow{4}{*}{ LN3 } & 40452 & 55635 & 147021 \\
\hline LNE & & 51746 & 89428 & 197988 \\
\hline LN5 & & 54496 & 84147 & 178665 \\
\cline { 3 - 5 } & 52768 & 114190 & 271398 \\
\hline
\end{tabular}

\section{RESULTS}

Values of maximal loading for each type of beam are presented in the Fig. 4(a) and the maximal deflection values are shown in the Fig. 4(b). EXP-MAX shows maximal deflection under maximal force, EXP-BENDING shows deflections under force according formula (4), both gained form experimental data, and XFEM shows values of deflections gained from XFEM analysis. 


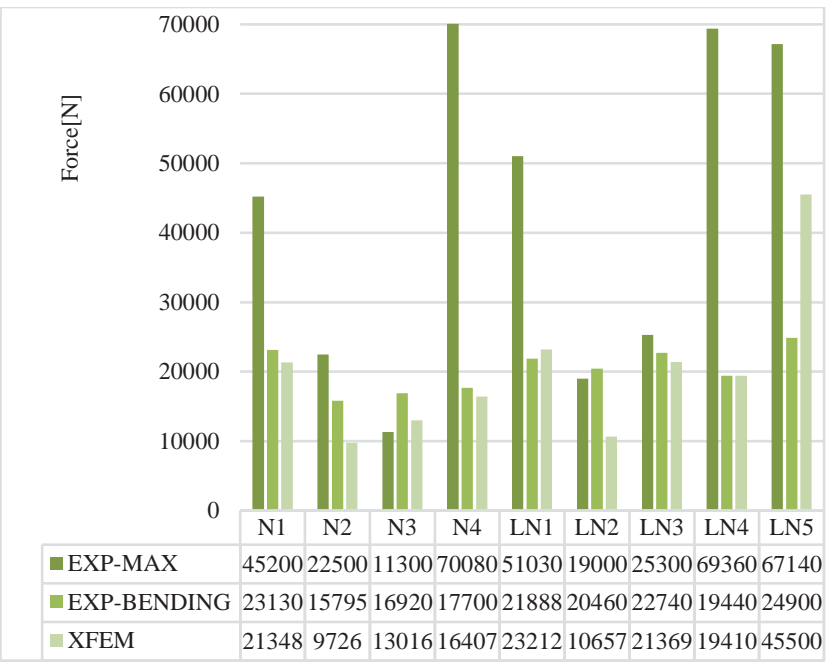

(a)

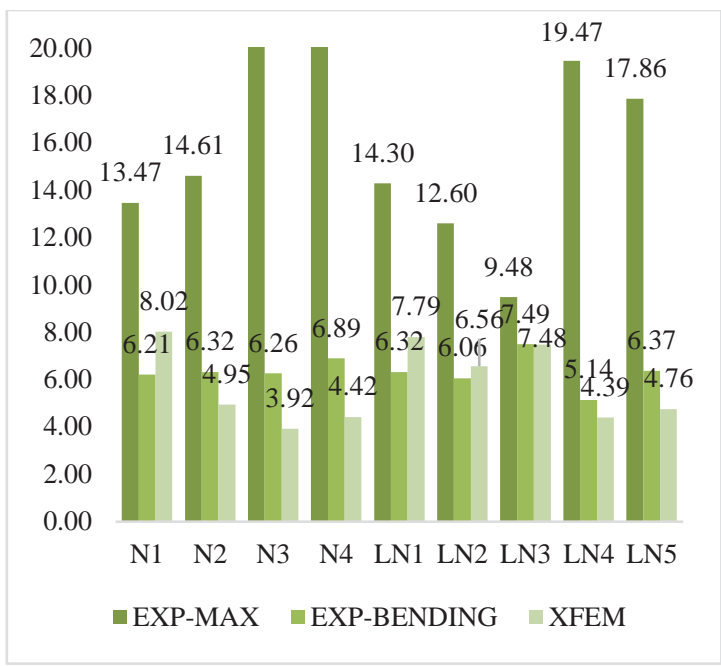

(b)

FIGURE 4. (a) Maximal values of loading forces based on the beam and flaw type [N], (b) Maximal values of deflection [mm]

Diagrams of displacement of beams under force of 20480N (maximal bending force) for experimental results, and maximal force obtained from XFEM analysis for XFEM results respectively are shown. On horizontal axis are $\mathrm{x}$ coordinates of beam span. Coordinates $\mathrm{x}=0.15 \mathrm{~m} ; 1.55 \mathrm{~m}$ represent a left and right beam's fix, $\mathrm{x}=0.65 \mathrm{~m} ; 1.15 \mathrm{~m}$ represent place where loads were applied. Deflection Diagrams for sawn beams are presented in Fig. 5(a), for glued laminated beams in Fig. 5(b) "XFEM" means that values were retrieved from XFEM analysis and "EXP" are experimental values.

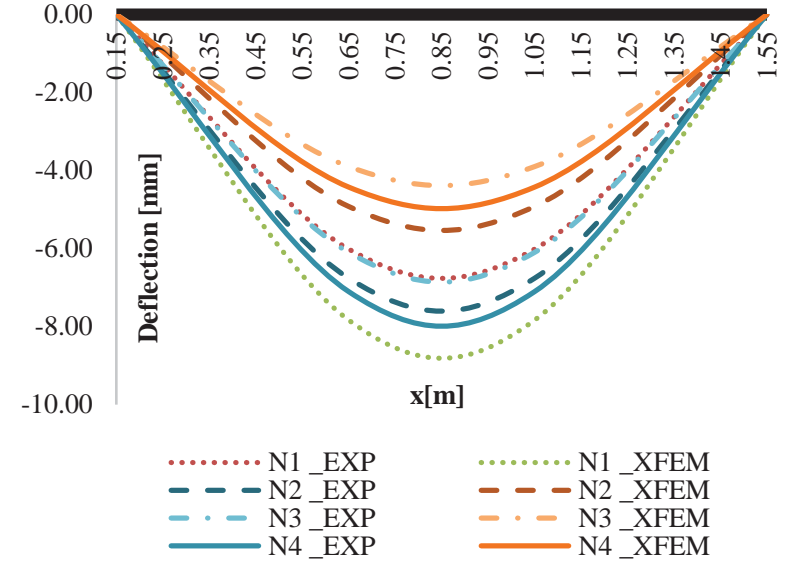

(a)

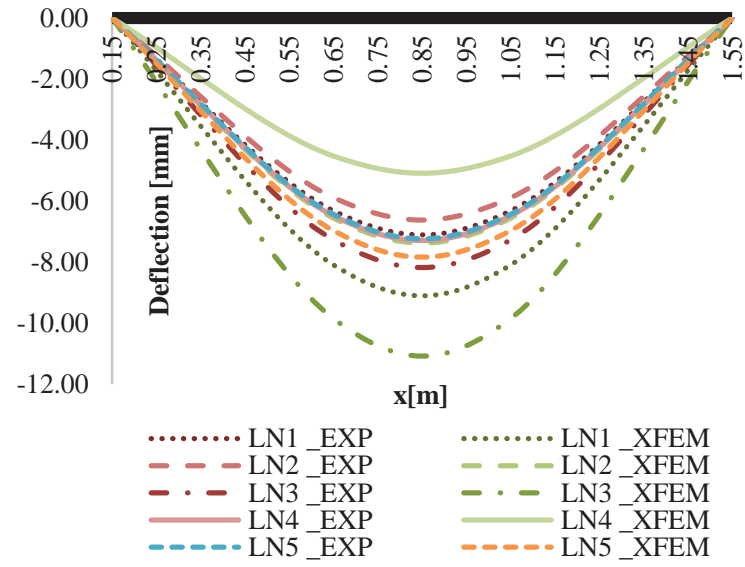

(b)

FIGURE 5. Deflection diagrams for sawn beams (a), and for glued laminated beams (b)

\section{DISCUSSION}

The comparison of experimental values of load-carrying capacity for beams without and with flaws, sawn and glued laminated beams is shown in the Fig. 6(a). Beams without flaws (N1 and LN1) were taken as referential. Number "2" represents beams with the vertical crack in the middle of span (Fig. 3 (b)), "3" beams with an oblique crack (Fig. 3 (c)), "4" beams with a circular hole (Fig. 3 (d)), and " 5 " beams with horizontal crack (Fig. 3 (e)). The resistance of beam decreased about $45 \%$, for the sawn beam and $63 \%$ for glued laminated beams when beams contained the vertical crack in the middle of span. The resistance of beam decreased about $75 \%, 78 \%$ for the sawn beam, glued laminated beam respectively when beams contained the oblique crack. The resistance of beam increased about $55 \%, 36 \%$ for the 
sawn beam, glulam respectively when beams contained the circular hole and it increased 32\% for glulam beam with the horizontal crack. This particular case will be subjected to additional studies.

The worst influence on load- carrying capacity had the oblique crack for sawn beams and vertical crack for glued laminated beams. Since both flaws had a sharp shape in these cases, early failure was expected. It may be caused by concentrated stress fields near the crack tip. On the contrary, load carrying capacity increased for beams with the circular hole for both types of beams. The circular shape of the flaw caused this. In this case, stress concertation fields are smaller and the shape helps with stress propagation in near area of the flaw.

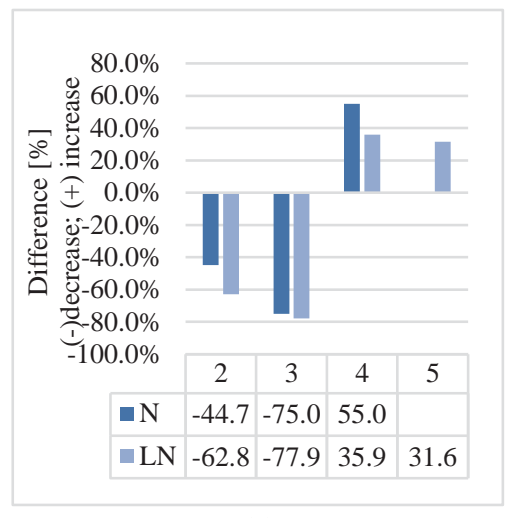

(a)

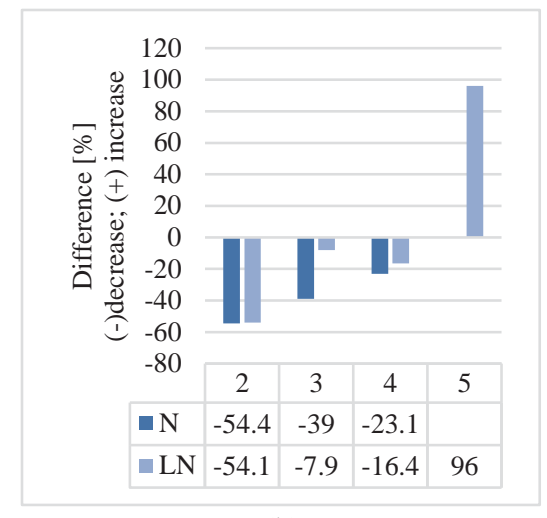

(b)

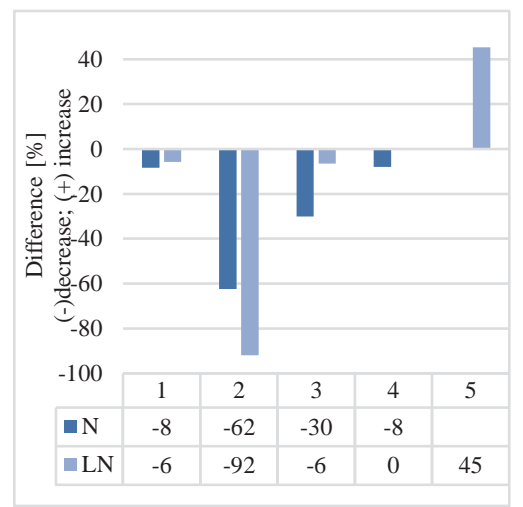

(c)

FIGURE 6. (a) The comparison of experimental values of forces: referential beams N1 and LN1 vs. beams with flaws (2, 3, 4, 5), (b) the comparison of XFEM values of forces: referential beams N1 and LN1 vs. beams with flaws (2, 3, 4, 5), (c) The comparison of maximal experimental versus XFEM values of forces

The comparison of computational values of forces for beams without and with flaws, sawn beams and glued laminated beams is shown in the Fig. 6 (b). Beams without a flaw (N1 and LN1) were taken as referential. Numbers "2", "3", "4", and "5" have same meaning as in previous case. The resistance of beam decreased about $54 \%$ for the sawn beam, glulam respectively when beams contained the vertical crack in the middle of span. The resistance of beam decreased about 39\%, 16\% for the sawn beam, glulam respectively when beams contained the oblique crack. The resistance of beam decreased about $23 \%, 8 \%$ for the sawn beam, glulam respectively when beams contained the circular hole and it significantly increased about $96 \%$ for glulam beam with the horizontal crack. In the case of LN5, no jump in damage dissipation energy occurred during XFEM analysis.

The worst influence had the vertical crack for sawn as well as for glued laminated beams with using XFEM method. In this case, numerical values are comparable with experimental. Load-carrying capacity decreased for beams however, decrease was smaller than in experimental testing. This may be caused due to set up crack initialization and fractured criterions. Also in numerical analysis only linear mechanical characteristic were considered.

The comparison of experimental bending values versus XFEM values of forces is in Fig. 6(c). Experimental bending values were referential, since bending strength is essential in timber beam designing. In all cases decrease of load-carrying capacity occurred, except LN5 beam. For both types of beams ( $\mathrm{N}$ and LN), the vertical crack in the middle of beams' span had the worst influence on load-carrying capacity. The capacity decreased about $62 \%$, $92 \%$ for N2, LN2 beams respectively. For N3, LN3 beams which contained the oblique crack, load-carrying capacity decreased about 30\%, 6\% respectively. In case of beams with no flaw N1, LN1 and sawn beam with the circular holes N4 no significant changes occurred. In these cases, load-carrying capacity decreased 8\%, 6\%, and 8\%. In case of LN4 no decrease occurred.

Since only decrease in load-carrying capacity occurred for beams N1-4 and LN1-LN4 we can say that by using XFEM analysis we obtain reliable results in the area of linear behaviour of wood. Therefore, this method is suitable for solving these types of flaws. In the LN5 case increase occurred.

No jump in dissipation energy and increase in load-carrying capacity occurred in LN5 beam. This might be caused by stress concentration near the tip of crack, position of the crack; however, it might be also due to errors in FEM analysis. For understanding why this positive influence occurred in this case, it is necessary to conduct more simulations with this type of flaw. 


\section{ACKNOWLEDGMENTS}

This work was supported by VEGA project 1/1186/12 and scholarship from "Nadacia Tatrabanky- Studenti do sveta 2015”.

\section{REFERENCES}

1. Anderson, T.L. Fracture Mechanics. Fundamental and Applications. 3. (Boca Raton : CRC Pres. Taylor \& Francis Group, 2005). p. 611. 13: 978-1-4200-5821-5.

2. Forest Products Laboratory, Wood Handbook. Wood as an Engineering Material. (Madison : United States Department of Agriculture Forest Service, 2010) p. 508. Centennial Edition.

3. Aicher, S., Gustafsson, P.J., Haller, P., Petersson, H. Lund, Fracture mechanics models for strength analysis of timber beams with hole ore notch. (Structural Mechanics, LTH, Sweden, 2002, A Report of RILEM TC-133. ISRN LUTVDG/TVSM--02/7134--SE ( 1-1 04)) ISSN 0281-6679.

4. Irwin, G.R., "Onset of Fast Crack Propagation in High Strength Steel and Aluminium Alloys" in Research Conference Proceedings, 1956, Sagamore Vol. 2, pp. 289-305.

5. Griffith, A.A., "The Phenomena of Rupture and Flow in Solids" in Philosophical Transactions of the Royal Society of London, Vol. 221, 1920, Vol. Series A., pp.163- 198.

6. Sih, G.C., Handbook of stress intensity factors. (Bethlehem, Pennsylvania : Lehigh University, 1973).

7. Tada, H., Paris, P.C. and Irwin, G.R., The stress analysis of crack, handbook of stress intensity factors. (Betlehem, Pennsylvania: Lehigh University , 1979).

8. $\quad$ EN 338 Structural timber - Strength classes (2016).

9. EN 14080:2013 Timber structures - Glued laminated timber and glued solid (2013).

10. BS EN 301:2013 Adhesives.

11. STN EN 1995. Eurocode 5: Design of timber structures (2008).

12. 6.14-4, Abaqus/CAE Users gide.

13. Belytschko, T., Black, T., "Elastic Crack Growth in Finite Elements with Minimal Remeshing" in International Journal for Numerical Methods in Engineering (1999), Vol. 45, pp. 601-620.

14. Melenk, J., I. Babuska, "The Partition of Unity Finite Element Method: Basic Theory and Applications" in Computer Methods in Applied Mechanics and Engineering, (1996) Vol. 39, pp. 289-314.

15. Benzeggagh, M., and M. Kenane, "Measurement of Mixed-Mode Delamination Fracture Toughness of Unidirectional Glass/Epoxy Composites with Mixed-Mode Bending Apparatus" in Composite Science and Technology, (1996) Vol. 56, pp. 439-449.

16. Haller P., Putzger R., "Fracture Energy in Mode I and Mode II of Reinforced Wood" in Proceedings of the 2nd Colloquium on Textile Reinforced Structures, (Technische Universität Dresden: Eigenverlag, 2003. (CTRS2)), pp. 247-258. 